An International Multidisciplinary Journal, Ethiopia Vol. 7 (3), Serial No. 30, July, 2013:292-307

ISSN 1994-9057 (Print)

ISSN 2070--0083 (Online)

DOI: http://dx.doi.org/10.4314/afrrev.v7i3.21

\title{
Social Effects of Organisational Restructuring on Employee Workplace Attitudes in Selected Manufacturing Industries in Nigeria
}

Longe, Olukayode - Department of Sociology, Ekiti State University, Ado-Ekiti, Ekiti State, Nigeria

E-mail:premiumkay@yahoo.com

\begin{abstract}
This study examined the influence of the social impact of organisational restructuring on employee workplace attitudes. A sample of 725 employees drawn through stratified random sampling technique from four (4) manufacturing organisations which had been involved in an intensive restructuring process participated in the study. Questionnaire was the major instrument employed for data collection. Data were analysed using both descriptive and inferential statistics. The main hypothesis of the study was tested and result of finding showed a non-significant association between social effects of organisational restructuring and employee work-related attitudes. Furthermore, it was discovered that the general constellation of employee work -related attitudes, both the intrinsic and extrinsic aspects about the greater parts of their work-values and roles suffered satisfaction and commitment in post restructuring context. The significance of the findings of this study was discussed and their implications in the Nigerian manufacturing environment highlighted.
\end{abstract}


Key words: Organisational Restructuring, Workplace Attitude, Adaptation and Performance.

\section{Introduction}

The increasingly competitive market pressure and changing business environment have necessitated management in organisations to continuously search for high commitment work-system. Besides, globalisation and information technology further add pressures to the need of constantly reinventing ways to compete (Zupan and Ugrojensek, 2004). Thus, it is widely accepted that an intervention such as organisational restructuring can significantly contribute towards attitude changes among employees, which in turn affects workforce loyalty, productivity and morale either positively or negatively, depending on the nature and direction of the attitude change (CEC, 2008; Brand and Wilson, 2000; Luthan and Sommer, 1999; and Donaldson, 1994). As such, organisational restructuring is often seen as the most favoured option when the challenges of change are felt in workorganisations. This revolutionary managerial approach is aimed at the improvement of organisations for the purpose of enhancing effectiveness and responsiveness to environmental changes through better realignment of employee work attitude and adaptation in the work environment.

According to Dzawanda (2007), organisational restructuring is the fundamental changes made to the structural properties of the organisation. More importantly, it is often framed to connote a proactive intention on the part of management aimed at exploiting new opportunities in the organisational environment. In other words, it is directed at altering the key organisational variables that can affect the component of the management social structure and organisational members' work-behaviours and attitudes in the workplace. Although, the basic assumption behind this novel managerial approach is that it will inject new work-life, interest and enthusiasm into the organisation and members therein, it is often embedded in complexities which put strain and pressure on the existing work-attitudes of the employees in organisations. Available literature have in fact revealed that what is gained in terms of performance imperative is lost in other areas (Hirsch and Sourcey, 2006; Loosebikan, 2005; Neilson and Sharma, 2004; Kim, 2003; Ruet,2003; and Frenkel, 2003). This is as a result of the complex ambiguities inherent in the implementation of this radical change initiative programme which involves taking crucial decisions, the depth and scope of which intimately impact on employees at all levels in the organisation. 
Workplace attitudes are organisations of interrelated beliefs of individuals around a common focus and predisposition to respond in certain ways to work situations (Ogundele, 2005). If this assertion is correct, it is almost impossible to implement organisational restructuring without impacting either negatively or positively on the prevailing employee attitudes within the organisation. For this reason, most employees in post-restructuring context are incessantly dissatisfied with the changing condition of work and finding it more difficult to sustain loyalty by adjusting positively to the discomforts which accompanied restructuring in the workplace (Longe, 2012). This notwithstanding, employees still jostle to impress in their new work roles by adopting various coping strategies, through change of attitudes, but these create further disenchantment for them in organisations. Relatedly, many organisations that restructured in order to increase productivity and gain competitive advantage are finding that what they have gained is a depressed, anxious and angry workforce at a time when they need spirit and creativity to ensure future success (Lewin and Johnston, 2000). Thus, the critical challenge facing restructured organisations is the ability of the employees to adjust to the prevailing work situation by diminishing of old work-roles and developing new and propitious work attitudes that are consistent with goals and standards in the work-situation.

Given the concomitant social dysfunctions of organisational restructuring, the logical and pertinent question to ask at this juncture is that; to what extent are employees responding favourably to greater responsibilities and more challenging work roles in post-restructuring context in organisations? The answer to this question is bound up with the nature of the work-related attitudes of employees in the organisation. On one level of thinking, changes that require shift in employees' attitudes are not easily accepted by them in the workplace. On the other level of thinking, employees need to adopt new attitudinal response that will allow them cope with the changing work milieu in the organisational environment. In such circumstance, manufacturing organisations need employees who can develop favourable attitudes through which fitness can be enhanced to accommodate the changing extant conditions of work-life in post-restructuring context. This implies a gradual process of developing readiness of attitudinal realignment on the part of employees in order to readjust or remodel positively to the situational reality in organisational environment. It is also suggestive of a situation whereby employees adopt a better work attitudinal approach in understanding and 
accepting of the changing work condition in order to overcome the prevailing obstacles of restructuring in the workplace.

The manufacturing industry which is the focal point of this study occupies a position of pre-eminence in the industrial scale of preference in any nation. The sector propels all other sectors and more than any industry helps to develop rapidly the much needed entrepreneurial and managerial skills in national economies. It has remained one of the most powerful engines for necessary economic growth and development that need the required attention by all and sundry as how it performs. What therefore aroused interest in this study are the unintended social effects and dysfunctions created as aftermath of restructuring in the manufacturing industry. Since the radical managerial programme may be inevitable for repositioning of business organisations, what may be required is the positive response of employees in terms of their positive attitudinal disposition to work. Thus, the thrust of this study is to investigate the social outcomes of organisational restructuring on employees work related attitudes in the manufacturing industry.

\section{Literature review}

The review of literature presented an overview of organisational restructuring and employee work related attitudes. According to Ogunbameru (2007), organisational restructuring is a term used to encompass a whole range of activities from employees downsizing, lay-off, delayering, re-engineering to consolidation and mergers of organisational unit. In this perspective, the essence is basically to enhance performance by realigning the organisational social structure and work attitudes of employees therein to ensure a proper fit in the work-situation. This involves the act of transforming work -behaviours and attitudes, dismantling or replacing the existing management structure by relevant goal oriented and competitive structure that will satisfy the needs of both the organisation and employees in the workplace. In this way, organisational restructuring is concerned with important aspects of managerial decisions to make changes in several realms of the workplace such as, task-design, work process and authority relations in order to produce a fitter and more responsive organisation (Isamah, 2004). Consistent therefore, with the actual development in industries and business firms literature has suggested the social effects of organisational restructuring as shortened job tenure and precarious work arrangement (Quinlan, 2007); significant confusion of work-roles (Frenkel, 2003); heightened workload and role overload (Gaughan, 2002) dropping employee retention rate and diminishing morale ( Nickels, 2002). 
To this end, a growing number of empirical evidence tends to reveal some significant dysfunctions of the radical management model which served as inhibitory dynamic preventing restructured organisations and their employees from accomplishing the intended objectives in organisations. For instance, Asok (2005), found evidence of damaged morale of managerial and nonmanagerial personnel based on indicators like lack of employee commitment, poor job satisfaction, excessive labour turn-over in post-restructuring context in a multi-activity organisation with presence spanning four continents: Asia, Europe, America, and Africa. Burchel, Ladipo and Wilkinson, (2002) equated organisational restructuring with job insecurity and argued that the consequence for an organisation on the employees in terms of commitment and willingness to work beyond contracts are damaging.

Hirsch and Sourcey, (2006) examined the socio-psychological impact of restructuring on employees work-related attitude (work satisfaction and trust) including their antecedents in the work-environment. Trust and work satisfaction were tracked three months before and after the restructuring for the varying types of changes that were initiated. Both trust and satisfaction of employees working in the organisation declined significantly when compared to the pre-restructuring level. Broom, Souzar, Strazdius, Butterworth, Paslow and Rodges (2006) in a study conducted in Australia among middle aged employees found that the combination of role-overload and job insecurity, which are upshots of organisational restructuring resulted in markedly higher odds of socio-psychological attitudinal problems for the workforce.

Parry (2003) conducted a study on restructuring in the coal mining industries in South Wales valley and submitted that the outcome has broken social cohesion and integration among the work community, creating serious jobloss and low level of commitment to duty. Also in Britain, Nickels (2002) in a health care organisation found that employees suffered poor morale and work satisfaction as a result of the necessary evil of creative destruction of organisational restructuring. In a Swedish study, Isaksson, Hellgreen and Patterson, (2000) on repeated downsizing and other forms of restructuring in the retailing industry found that older employees were more likely to experience negative and long term symptoms of attitudinal frustration within the organisation. Thus, the radical change management model often carries with it shared realities of impaired work-related attitudes in the organisational environment. 
In sum, organisational restructuring is assumed to be a complex activity with lots of diverse challenges to contend with in an organisation. Although, the revolutionary managerial approach does not possess the intensity of forest fire, it usually contains strong potentials of ontological distrain and heightened discontentment for employees with definite implications for work-attitude and performance in organisations (Longe, 2012).

\section{Study hypothesis}

The study aimed at determining whether workplace attitudes were in fact influenced by restructuring process in the manufacturing organisations. Based on that objective and the comprehensive review of the literature, the following hypotheses were formulated and tested.

Ho There is no significant relationship between social effects of organisational restructuring and employee work related attitudes.

Hi There is significant relationship between social effects of organisational restructuring and employee work-related attitudes.

\section{Research method}

The survey was conducted in four purposively selected manufacturing firms, which had been involved in a process of extensive workplace restructuring within the past five years. The population of the target companies where the data were obtained was 3200. Using an appropriate statistical formula for sample selection, stratified random sampling technique was employed to select 800 respondents. The basic criterion for inclusion in the sample was job rank and length of service of not below 5 years. The total population of employees in the register of selected organisations was used as the sampling frame.

Questionnaire was the main instrument of data collection for the study. The researcher distributed 800 copies of questionnaire and 725 were found to be valid and useable for analysis with response rate of 91.6\%. Employee workplace attitude questionnaire was designed to determine the workforce general feel or perception of the social outcomes of organisational restructuring. The manifest and latent contents of all the questions were to ensure that respondents describe the extent of their vulnerability to both the prospective and retrospective issues related to the unintended social impact of organisational restructuring. Except for the questions on employee personal attributes, the 38-item questionnaire utilizes the Likert scale format showing strongly disagree to strongly agree with the numerical value of $1-5$ 
respectively. In order to explore the indicators of workplace attitudes, work commitment, work-satisfaction and work-involvement of employees were used as related proxies. Thus, the dependent variable (employee work-related attitudes) was measured using a composite mean score value derived from these proxies. The same procedure was adopted for the indicators of independent variable (social effects of organisational restructuring).

Data analysis was carried out using simple percentage counts, frequency tables, mean and standard deviation to present responses to survey questions especially those related to socio-demographic characteristics and other issues explored in the questionnaire. A non-parametric measure of chi-square test was used to determine the social effects of organisational restructuring on employee work-related attitudes.

\section{Results of findings}

Findings on the socio-demographic attributes of the respondents showed a mean age of 33.3 years with standard deviation of 6.85 years. The gender of respondents revealed a disproportionate representation, where male constituted $67.4 \%$ of the sampled population, while female respondents accounted for $(32.6 \%)$ in the research study. This presents a ratio of $2: 1$ across the gender group skewed in favour of males. This is not unconnected with the low female participation in the industrial labour market as confirmed by earlier findings that majority of employees in manufacturing industry in Nigeria are males (FITC, 2011). On marital status, more than seven (7) out of ten (10) respondents that is, $(71 \%)$ were married, less than one-quarter $(23.2 \%)$ were single and divorced (4.8\%). This is somehow significant, given the perception in the Nigerian society that being married often confers responsibility on individuals, with implication on their work attitude and adaptive response to change in organisations.

On educational status, findings showed that majority $(68.9 \%)$ of the respondents had secondary education (WASC) followed by OND/NCE (12.1\%) professional qualification (9.0\%) and HND/First Degree (5.9\%). These findings attested to the literacy level of the respondents. Data on length of service of the respondents presented a mean of 9.9 years, with standard deviation of 3.6years. The implication of this finding is that over half of the study sample (51.2\%) had worked in the selected manufacturing organisations for not less than ten (10) years. The relative placement of each employee in the social organisation of work (that is in terms of job status) was also enumerated. A significant majority $(84.4 \%)$ of the respondents were 
in the junior level rank followed by middle level officers (11.9\%) and management staff $(3.7 \%)$. This indicates that a bulk proportion of the respondents were in the junior cadre category.

\section{Test of hypothesis}

The main thesis for the study held on the assumption that social effects of the restructuring process would influence employee work-place attitudes using work commitment, work satisfaction and work involvement as proxies. Thus, the dependent variable, (workplace attitude) was measured using a composite score derived from these proxies. Indices of workplace attitudes were measured using Likert scale format for the twenty-three different facets of questions provided with contrariety options assigned with numerical value of one to five respectively. To build a composite weight for the proxies of workplace attitudes, the total score value of these indices were pulled together and computed, whereby each of the respondents could be categorised into bi-polar classification of:

(i) Not committed or committed

(ii) Not satisfied or satisfied

(iii) Not involved or involved.

The same procedure was adopted for the indicator of the independent (predictor) variable (social effects of organisational restructuring) using the same pattern of computation in order to allow the classification of outcomes into two categories as either negative social effects or positive social effects. Thus, a bivariate analysis of the predictor and response variables were carried out using cross-tabulation and subjected to non-parametric chi-square statistical test.

Work commitment was first used as the response variable in testing the study hypothesis. Data presented in Table 1 shows that majority $(52.3 \%)$ of the respondents who claimed negative social effects were committed to their job. Correspondingly, almost the same proportion (50.8\%) of those who asserted positive social effects was also committed. As such, the work commitment pattern tends to be the same, with only slight disparity for the respondents who signified negative social effects and those who agreed to positive social effects. Thus, no significant difference was established between the social effects of organisational restructuring and work commitment of employees. $\left(\chi^{2}=1.10 \mathrm{df} 1, \mathrm{p}>0.05\right)$ On the second proxy of the dependent variable (work satisfaction of employees), (51.5\%) of respondents who attested to negative social effects were satisfied. In contrast, almost the same 
representation $(51.2 \%)$ of respondents who agreed to positive social effects was also satisfied. It was observed that in both instances, there seems to be resemblance in the responses with no significant variation obtained. Therefore, there was no significant relationship between the social outcomes of organisational restructuring and work satisfaction of employees.

$$
\left(\chi^{2}=1.59, \text { df } 1,>0.05\right) .
$$

Furthermore, on the third variable used as proxy, (employee work involvement) showed no statistically significant association with the social effects of organisational restructuring $\left(\chi^{2}=62.07\right.$, df1, $\left.p>0.05\right)$. Over half of the sampled population, that is, $(53.8 \%)$ of the respondents who signified their acceptance of negative social effects were involved on the job while respondents within the category of those who claimed positive social effects $(52.1 \%)$ of them were also involved. Similarly, a low group (46.2\%) who agreed to negative social effects were not involved while at the other side (47.9\%) who agreed to positive social effects were not involved. Thus, the differences in the two sides were not statistically significant. This shows that the relationship between the social effects of organisational restructuring and employee work involvement was not statistically significant.

Table 1: Chi-Square Test of Relationship between Social Effects of organisational Restructuring and Employees Work-place Attitudes

\begin{tabular}{|c|c|c|c|c|}
\hline \multirow{3}{*}{$\begin{array}{l}\text { Employee Workplace } \\
\text { Attitude } \\
\text { Work Commitment }\end{array}$} & \multicolumn{4}{|c|}{ Social effects of Organisational Restructuring } \\
\hline & \multicolumn{2}{|c|}{-ve Outcome } & \multicolumn{2}{|c|}{ +ve Outcome } \\
\hline & $\mathrm{N}$ & $\%$ & $\mathrm{~N}$ & $\%$ \\
\hline Not Committed & 227 & 49.2 & 126 & 47.7 \\
\hline Committed & 234 & 50.8 & 138 & 52.3 \\
\hline Total & 461 & 100 & 264 & 100 \\
\hline \multicolumn{5}{|c|}{$\chi^{2}=1.103, \mathrm{df}=1, \mathrm{p}$ value $=0.294$} \\
\hline \multicolumn{5}{|l|}{ Work Satisfaction } \\
\hline Not Satisfied & 225 & 48.8 & 128 & 48.5 \\
\hline Satisfied & 236 & 51.2 & 136 & 51.5 \\
\hline Total & 461 & 100 & 264 & 100 \\
\hline \multicolumn{5}{|c|}{$\chi^{2}=1.592, \mathrm{df}=1, \mathrm{p}$ value $=0.207$} \\
\hline \multicolumn{5}{|l|}{ Work Involvement } \\
\hline Not Involved & 221 & 47.9 & 122 & 46.2 \\
\hline Involved & 240 & 52.1 & 142 & 53.8 \\
\hline Total & 461 & 100 & 264 & 100 \\
\hline$\chi^{2}=62.075, \mathrm{~d}$ & 0.216 & & & \\
\hline
\end{tabular}

Source: Author's Survey, 2013. 
In short, all the covariates of work-related attitudes used as proxies, that is work commitment, work satisfaction, work involvement showed no statistically significant relationship with the social effects of organisational restructuring. Thus, the alternative hypothesis was therefore rejected, while the null hypothesis was accepted. The picture which emerges from these findings is not unlikely considering the rhetorical consequences and sideeffects of organisational restructuring on employees in the workplace, particularly in the developing nations. Employees have become insouciant and lacked satisfaction at work as a result of the concomitant adverse effects of organisational restructuring, and now have more concern for job security and work-life survival

\section{Discussion}

The present study was planned to investigate the social repercussions of organisational restructuring on employees' work-related attitudes in the manufacturing environment. The path analytic cross-tabulation with chisquare statistical test did not predict any significant relationship between the measures of the radical change management model and employee workrelated attitudes thereby, confirming the operational hypothesis which assumes that the restructuring process will not affect employee workplace attitudes in the post-restructuring context. The weight of evidence from this study clearly deviated from the findings of Brand and Wilson (2000) which indicated that the organisational restructuring process affected the employees' respective attitudes in a positive manner. According to them, employees were affected directly both personal and professional by the changes that were implemented that they identified strongly with the organisation. The findings of this present study seem to refute these claims because empirical evidence that emerged from our study clearly indicated the contrary.

However, consistent with some findings in the literature, the present study mirrored the work of Quinlan, (2007); Hirsch and Sourcey (2006) and Asok (2005) and also have the same semblance with the earlier studies of Broom, Dsousa, Strazdius, Butterworth, Parslow and Rodger (2006); Parry (2003); and Nickels (2002) that restructuring process in organisation is ridden with various ambiguity and potentially distributing outcomes and the consequence for an organisation and employees in term of commitment and willingness to work are damaging. This position was further buttressed by the results of previous studies carried out by Burchell, Ladipo and Wilkson, (2002), 
Mckinley and Scherer, (2000) and Lewins and Johnston (2000) that the frequent product of organisational restructuring is a significant reduction in employee work effort, job satisfaction and job commitment. As such, employees had become disenchanted with the condition of work which confered additional workload and responsibility on them. However, this view somewhat contradicted the report of Brand and Wilson (2000) in which it is said that employees identified strongly with the organisation after the restructuring process and did not seek alternative employment.

The converse of this is the outcome of our finding that the condition of work as aftermath of organisational restructuring became unbearable for employees, thereby making it extremely difficult for them to exhibit much significance in the workplace. They had become unmoved and indifferent of the side-effects of the restructuring process out of necessity to keep their jobs at the face of increasing uncertainty and growing rate of employment instability in the manufacturing industries in Nigeria. Besides, the nation's economy has almost moved to a jobless state where most manufacturing organisations no longer offer long term career employment. Thus, the general employees' constellation of workplace attitudes about the greater aspects of their work, both the intrinsic and extrinsic aspects of the jobs lacked satisfaction.

In essence, some important implications emerged from this study. Firstly, the general managerial argument that the reduction of staff strength and other concomitant side-effects of organisational restructuring are opportunities for surviving employees to make themselves more suitable by developing favourable work attitudes that are consistent with the goals and standards of the organisation are only imaginary and illusory thoughts. Empirical evidence from this study has shown that it is erroneous to assume that the relief of not losing one's job will overshadow any negative feelings one might have against the organisations after the restructuring. It is only when employees' fear and anxiety are low, that employees' therapy may facilitate well-disposed attitudinal adjustment in the workplace. Secondly, it is constant that employees will likely be confronted with more and more challenges in any restructuring process, except management provides the necessary moderating support in order to ensure a smooth rhythm during and after the post restructuring period, employees will continue to display unbenign workplace-attitude. This makes it expedient on the part of management to always strive in concentrating on the need to promote the 
best managerial practice in pre and post restructuring period in the workplace.

\section{Conclusion and recommendations}

The main aim of this study is to test the validity in the Nigerian context of the wide acclamation for restructuring as an organisational saviour in the manufacturing industries in the global workplace. Although, the radical managerial programme is a valuable transformational tool that has practical relevance in all organisational sectors, it has however proved to be almost a chaos in Nigerian manufacturing environment, disrupting and inhibiting employee work attitude and performance which it was intentionally instituted to enhance and improve. The study has also shown that there is merit in looking at manufacturing organisations as the radical change management model affects employee workplace attitudes. The interpretation that emerges, is that, organisational restructuring is a seemingly painful managerial strategy which carried with it, hard multiple realities for employees such as decreased job security, loss of work freedom and disappearance of work friendship.

In this regard, organisational restructuring intervention must be carefully implemented by management to help the workforce to be more refocused and involved in order to display a tangible difference in work attitude in postrestructuring era in the manufacturing environment. Accordingly, an employee centred workplace climate must be cultivated by management through guiding norms, values, expectations and policies to ensure the flexibility of the productive capacity of employees in post restructuring context in manufacturing organisations. Similarly, management style orientation should continuously emphasis proactiveness, realignment, support and occasional use of unilateral power to obtain compliance.

However, it appears that subject matter of the social impact of organisational restructuring and employee workplace attitude has been over flogged, but the emerging inferences from various research studies seem to suggest that the domain in organisational behaviour might become a phenomenon. It then goes without much saying that research study on organisational restructuring and workplace attitudes would continue to offer tremendous potential for further research, more so that the present study is relatively limited in scope and restricted to the manufacturing set up. Nevertheless, the study has not only offered a good insight into understanding of the Nigerian work related attitudes but also provided an integrative framework for future empirical research in this area of study. In this connection, the theme of the study can 
still be replicated either using the same interpretative method or using more quantitative orientated approach.

It also needs to be emphasised that the current study is not without some limitations despite the fact that the findings emanating there from had made modest contribution to the existing literature. Most of the studies on socialeffects of organisation restructuring and work related attitudes were generally carried out in advanced economies and social-cultural setting different from that of the Nigerian work environment. Socio-cultural norms and background often influence employee work related attitude in different circumstances and in different locations. As such, the depth of research in this area of concern in Nigeria makes it difficult for the present study to compare with other data sources and strengthen the theoretical base of our empirical analysis. Furthermore, the fact that the study data were derived from limited samples may make broad generalisations impossible. Despite these limitations, many of the generalisations that emerged from this study were suggestive and conclusive of the workplace and work-related attitudinal response of employees to the social problems of organisation restructuring in the manufacturing industries in the country. The case-study we used provided very much penetration into the organisational dynamics and functions of manufacturing companies in a reforming and developing economy such as Nigeria. 


\section{References}

Ashok, S. (2005). Mahut Group: A Failed Restructuring. Asian Case Research Journal vol.9 Issue (1) pp 1-23.

Broom D., Dsouza R., Strazdins L., Butterworth P., Parslow R., \& Rodger, B. (2006). The Lesser Evil or Bad Jobs or Unemployment - A Survey of Middle Aged Australians during Organisational Restructuring, Social Science and Medicine Journal, vol. 63 pp575586.

Burchell B., Ladipo, D. \& Wilkinson, F. (2002). Job Insecurity and Work Intensification. London: Routledge Press.

Burke, R. Carry, L. \& Copper D. (2000). The Organisation in CrisisDownsizing, Restructuring and Privatization. Malden, Massachusetts, USA: Blackwell Business Publishers.

CEC (2002). Anticipating and Managing Change: A Dynamic Approach to the Social Aspects of Workplace Restructuring. Commission of European Commission Paper, Brussels, Germany.

CEC (2008). Restructuring and Employment: The Contribution of the European Union. Commission of European Communities Commission- Working Paper. Brussels, Germany.

Donaldson, G. (1994). Corporate Restructuring: Managing the Change Process from Within. Harvard: Harvard Business School Press. First edition, 658,1612 O/S.

Dzwanda, B. (2007). The Restructuring and Privatization Process. Paper Presented to the Union of African Railways, 7th Meeting on Restructuring and Privatization-Kinshasa, Congo.

FITC, (2011). Gender Relations Management in the Workplace; The Nigerian Experience. Lagos, Nigeria: Financial Institutions Training Centre Publication.

Frenkel, S. (2003). The Embedded Character of Organisational Restructuring, Journal of Works and Occupation. Vol. 30, pp135153.

Gaughan, P. (2002). Merger, Acquisition and Corporate Restructuring, New York, USA: Wiley Publications. 
Social Effects of Organisational Restructuring on Employee Workplace Attitudes ...

Hirsch, P. \& Sourcey, M. (2006). Organisational Restructuring and its Consequences - Rhetorical and Structural. Annual Review of Sociology vol. 32, August, pp 171-189.

Isakson, K., Hellgreen, I. Peterson, J. (2000). Repeated Downsizing Attitudes and Well-being for Surviving Personnel in a Swedish Retail Company. In Inisakson K., Hogstedt C., Eriksson, C. \& Therrell, T. (eds.) Health Effects of the New Labour Market. New York, USA: Kinwel/Plenum Press.

Isamah, A. (2004). Corporate Restructuring: The Challenge of Change as Motivator. Paper Delivered at the Management Training Retreat, Nigeria Air Space Management Agency, (NAMA), Lagos, Nigeria. May, 26th.

Kim, W. (2003). Economic Crisis, Downsizing and Lay Off Survivors Syndrome. Journal of Contemporary Asia vol. 33 April, pp449-464.

Kochan,T. \& Useem, M. (1992). Transforming Organisations. London: Oxford University Press.

Laosebikan, J. (2005). Re-engineering and Employees' Productivity in the Bank-Sector in Nigeria. Unpublished PhD Thesis. Department of Adult Education, University of Ibadan, Ibadan.

Lewin, J. \& Johnston, W. (2000). The Impact of Downsizing and Restructuring on Organisational Competitiveness - Competitiveness Review, January, pp 65-84.

Longe, O. J. (2012). Workplace Restructuring and Employee Adaptation in Selected Manufacturing Industries in Southwestern Nigeria. Ph.D Dissertation, Obafemi Awolowo University Ile-Ife, Nigeria.

McKinley, W. \& Scherer, A. (2000). Some Unanticipated Consequences of Organisational Restructuring. Academy of Management Review, October, vol. 25, no. 4 pp 735-752.

Neilson, G. \& Sharma, D. (2004). New Wave of Organisational Restructuring. Academy of Management Review. Vol. 2 June pp.

Nickels, J. (2002). The Invisible Cost of Organisational Restructuring. A Theory of Disengagement, University of Wales, College of Medicine and Centre for Health Leadership (Wales). 
Ogunbameru, O. (2007). Organisational Dynamics, Ibadan, Nigeria: Spectrum Books Limited.

Ogundele, O. (2005). Management and Organisation; Theory and Behaviour, Lagos: Molofin Nominee.

Omodele, I. (2009). Texile Industry Restructures, Nigerian Tribune. December, 23 pp 14.

Parry, J. (2003). Restructuring in the Former Coal Industry of the South Wales Valley. Work, Employment and Society, Vol. 17. British Sociological Association. February pp227-246.

Quillan, M. (2007). Organisational Restructuring (Downsizing OHS Regulation and Worker's Health and Well-being. Working paper No. 2 - National Research Centre for OHS regulation, Australian National University. South Wales, Sydney,Australia.

Ruet, J. (2003). Against the Current-Organisational Restructuring of State Electricity Board, New Delhi: Manohar.

Zypan, N. \& Ugrojensek, I. (2004). The Link Between Human Resource Management and Company Performance, Journal of East-West Business 10 (11) pp 105-119. 